\title{
APURDUTM
}

Euskal ikerketen aldizkaria | Revue d'études basques |

Revista de estudios vascos | Basque studies review

$13 \mid 2009$

Numéro XIII

\section{Euskal literaturaren historia - Ikuspegi historiografikoa}

L'histoire de la littérature basque en débat

Jean Casenave

\section{OpenEdition}

Journals

Édition électronique

URL : http://journals.openedition.org/lapurdum/1997

DOI : 10.4000/lapurdum. 1997

ISSN : 1965-0655

Éditeur

IKER

Édition imprimée

Date de publication : 1 février 2009

Pagination : 81-87

ISBN : 978-2-86781-409-X

ISSN : $1273-3830$

Référence électronique

Jean Casenave, «Euskal literaturaren historia - Ikuspegi historiografikoa », Lapurdum [Linean],

13 | 2009, Sarean emana----an 15 avril 2013, kontsultatu 22 avril 2019. URL : http://

journals.openedition.org/lapurdum/1997; DOI : 10.4000/lapurdum.1997 


\title{
Euskal literaturaren historia - Ikuspegi historiografikoa
}

\author{
Jon CASENAVE \\ Université Michel de Montaigne - Bordeaux 3
}

\section{Laburpena:}

Bigarren gerlatik landa idatziak izan dira Euskal Literaturaren Historiari buruzko lehen saio orokorrrak (K. Michelena, Historia de la literatura vasca, 1958, etb.), Historia literarioaren idatzarauen arabera.. XX-garren mendeko bigarren partean, euskal literaturaren historia egileek Europako herrialde guzietan erabilia zen ohizko eredu nazionala erakarri dute euskal eremura.

Estrukturalisten garaian historia literarioari egin zitzaizkion kritikak eta ordutik hona izan diren berriztapen metodologikoak euskal literaturari egokitu zituzten hemengo autore gehienek (I. Sarasola, Euskal literaturaren historia, 1971 / Historia social de la literatura vasca, 1976 ; J.M. Torrealdai, Euskal idazleak gaur, Historia social de la lengua y de la literatura vascas, 1977).

Geroztik, I. Aldekoa (Historia de la literatura vasca -2004- ; Euskal literaturaren historia -2008), J. Kortazar (Euskal literatura XX-garren mendean, 2003) eta M.J. Olaziregi (Euskal eleberriaren historia, 2002) bezalako ikerleek Historia literarioaren ohizko metodologiari gehitu diote giza zientziek eta testugintzak egin duten ekarpen zientifikoa.

Bestalde, ikerle horiek euskal literaturaren historia berritu dute kontutan hartuz azken hogeitahamar urte hauetan agertu diren obra nagusiak (B. Atxaga, R. Saizarbitoria, etb.) baita ere agerian emanez euskarazko sorkuntza literario mailan obra horiek eragin duten aldaketa paragabea.

\section{Résumé: L'histoire de la littérature basque en débat}

C'est après la seconde guerre mondiale que l'Histoire de la littérature basque a donné lieu aux premières synthèses d'envergure (K. Michelena, Historia de la literatura vasca, 1958, etc.) rédigées selon les principes méthodologiques de l'Histoire littéraire. Au cours de la seconde moitié du XXe siècle, les divers historiens de la littérature basque ont repris le traditionnel modèle national qui, depuis la fin du XIXe siècle, est commun à tous les pays européens.

Les critiques portées à l'Histoire littéraire durant la période structuraliste et le renouvellement méthodologique qui s'en est suivi ont été progressivement intégrés par les contributeurs successifs (I. Sarasola, Euskal literaturaren historia, 1971 / Historia social de la literatura vasca, 1976; J.M. Torrealdai, Euskal idazleak gaur, Historia social de la lengua y de la literatura vascas, 1977).

Ainsi, dans leurs ouvrages les plus récents, des chercheurs comme I. Aldekoa (Historia de la 
literatura vasca -2004- ; Euskal literaturaren historia -2008), J. Kortazar (Euskal literatura XX-garren mendean, 2003) ou M.J. Olaziregi (Euskal eleberriaren historia, 2002) s'appuient sur une large palette de concepts et de méthodes d'analyse issus des Sciences du texte, des Sciences sociales et de la «Nouvelle Histoire» pour compléter la méthodologie en usage dans l'Histoire littéraire.

Ces auteurs apportent aussi un important renouvellement de l'Histoire de la littérature basque dans la mesure où leurs travaux intègrent les œuvres maîtresses (B. Atxaga, R. Saizarbitoria, etc.) produites au cours de trente dernières années du XXe siècle, période qui a marqué un tournant sans précédent au plan historique dans le domaine de la création en langue basque.

Gako hitzak: Euskal literatura, ikuspegi historiografikoa, berriztapen metodologikoak.

Mots clés: Littérature basque, point de vue historiographique, renouvellements méthodologiques.

\section{Sarrera}

Duela hogeitabost urte, Txuma Lasagabasterrek azterketa sakon bat argitaratu zuen euskal literaturaren historiografiaz ("La historiografia literaria vasca - Aproximacion critico bibliografica"1983¹). Gogoeta horri segida bat eman nahi diot bainan, molde era bat deskriptiboan, doi doia aipatzeko garai hartarik hona zer egin den literaturaren historia mailan.

Orduz geroz, badirudi denentzat onargarria den eredu bat finkatua izan dela, hein batean "kontzentzuala" deitzen ahal duguna eta saiatuko naiz haren aurkezten adibide batzuen bitartez.

\section{Euskal literaturaren historia.}

Historia de la literatura vasca (1960): K. Mitxelenaren ekarpena.

Gorago aipatu dudan artikuluan, Tx. Lasagasterrek 1980-eko hamarkada arte argitaraturak izan diren Euskal Literaturaren Historien errepaso historiografikoa egin zuen, molde kronologikoan. Egin zuen zerrendatik, idazlan bat baizik ez zuen onartu egiazko idazlan zientifikotzat, K. Mitxelenaren Historia de la literatura vasca (1960) hain zuzen. Garai berean edo doi bat berantago agertu ziren L. Villasante ${ }^{2}$ edo Santi Oinandia ${ }^{3}$-ren historiak baztertu zituen ondoko bi arrazoinengatik : alde batetik euskarazko idatziaren historia eskaintzen zutelako eta ez euskal literaturarena ; bestaldetik, zehaztasun historiografikoa falta zitzaielako. Bigarren arrazoin horrengatik, 70-eko hamarkadan I. Sarasola ${ }^{4}$-k edo L.M. Mujika ${ }^{5}$-k argitaratu zituzten lanak ere gogorki kritikatu zituen.

Lasagabasterrek zion K. Mitxelenaren Historia de la literatura vasca (1960) dela euskal eremuan egina izan den lehen lan zehatza, arau historiografikoak behar bezala bete zituelako. Altxa ditzagun, liburu hartan aurkitzen diren ekarpen handienak : beste eremuetan erabiltzen diren ezaugarri nazionalak gurean eskas edo eztabaidagarri direlakoan, « ardatz linguistikoa » du hartzen oinarri gisa.

1. Lasagabaster Txuma, «La historiografia literaria vasca - Aproximacion critico bibliografica-“, Las literaturas de los Vascos, Deustoko Unibertsitatea arg., 2002.

2. Villasante Luis, Historia de la literatura vasca, Aranzazu arg., 1979.

3. Oinaindia Santiago, Euskal literatura, Etor arg, 1972-1990.

4. Sarasola Ibon, Euskal literaturaren historia, Lur arg., 1971.

5. Mujika Luis-Mari, Historia de la literatura euskerika, L.Haranbura-Altuna arg., 1979. 
Euskal literaturaren korpusa euskarazko testuekin bakarrik antolatu zuen, euskalki literarioek ekar zezaketen banaketa baino gorago ezartzen zuelarik, obra nagusiek beren artean sortzen eta egiten zuten batasuna. Historia literarioaren metodologia euskal adibideari egokituz, kriterio literarioa edo estetikoa erabili zuen kanon baten eraikitzeko eta erran daiteke «kanon bildu» edo «hertsi» bat osatu zuela ikusiz idazle nagusi gutti atxikitzen zituela bere pantheonean.

Bukatzeko, Tx. Lasagasterren ustez, literaturak gizartearekilako dituen harremanak behar bezala hartu zituen kondutan K. Mitxelenak, batez ere sorkuntza prozesuan.

\section{L.B. Orpustan: Précis d'Histoire littéraire basque (1996).}

Historia literarioaren metodologiak bere emaitza ontuena eman du XXgarren ondarrean, J.B. Oprustanen Précis d'Histoire littéraire $(1996)^{6}$ liburuarekin. Mitxelena abiatu zen bidetik ibilitzen da. Bainan, Mitxelenak egin zuen Historia osatzen du ondoko bi ponduetan : bat, autore nagusi gehienentzat azterketa monografikoa idazten du; bi, azterketa historiografikoa gehiago sakontzen $\mathrm{du}$, gertakari soziohistorikoek sorkuntzaren baitan ukan duten eragina barnatuz. Bestalde, ahal duelarik, Europa mailako mugimendu kultural eta estetikoekin izan diren harremanak lantzen ditu. Bistan dena, liburu hartan ere pundu eztabaidagarrri batzu badaude, hala nola periodizazioarena. Adibide gisa ondoko hau aipa dezagun: XIX-garren mende guzia garai bakar batean sar arazten du («Lâge romantique dans les Lettres basques -1816-1907»), beste historiolari guziek era ezberdin batez antolatzen eta zatitzen dutelarik. Bukatzeko, erran daiteke, Orpustan-en Euskal literaturaren historiak garai bat bat hesten duela euskal ikasketetan, hain zuzen historia literarioarena, bere oinarrizko zentzuan.

\section{Euskal literaturaren historia berritua.}

Tx. Lasabaster-ren azterketa kritikoa :

Lehen aipatu dudan ikerlanean, ("La historiografia literaria vasca - Aproximacion critico bibliografica-"1983), Tx. Lasagabasterrek Euskal literaturaren historiari buruz azterketa kritiko bat eskaini zuen. Ikuspegi historikoaz gain, bere ustez euskal literaturaren historiaren hobetzeko eta gaurkotzeko egin behar litezkeen ikerketen programa finkatu zuen:

- Lehen proposamena metodologikoa zen. Hark zion XX-garren mendeko azken partean eremu kultural garatuetan pentsatuak eta erabiliak izan ziren azterketa molde berriak erakarri behar zirela euskal eremura. Beraz, giza-zientzietatik (soziologia, psikanalisia, mentalitateen historia, etb.) eta testugintzatik (hizkuntzalaritza, semiotika, pragmatika, etb.) zetozen ekarpenak hartu eta erabili behar ziren. Hots, aldaketa metodoligikoa eta zientifikoa eskatzen zuen.

- Egiten zuen bigarren proposamena hauxe zen: hizkuntzaren historia eta literaturaren historiaren arteko lotura egin behar zela. Badirudi paradoxala dela proposamen hori : egia da luzaz literaturaren azterketa hizkuntzaren azterketaren menpean egon dela euskal ikasketan, Urkijok eta XX-garren mende hastapeneko ikerleek erabili duten "eredu filologikoa" hor dugula lekuko. Bainan, ez pentsa Lasagabasterrek atzera joan nahi zuenik bide hori erakutsiz. Ikerketa literarioek emeki emeki beren askatsuna ardietsi zuten eta ez zuen egoera berria zalantzan emaiten. Iduritzen zitzaion, euskal kontestu soziolinguistikoa kontutan hartu behar zela euskal literaturaren ikertzeko eta, batez ere egoera diglosikoak sorkuntza mailan zuen eragina.

6. Orpustan Jean-Baptiste., Précis d’histoire littéraire basque, Ed. Izpegi, 1996. 
- Hirugarren proposamena: hiruetatik zailena zen betetzeko. Euskal eremu kulturalean aspaldidanik egoera konplexua bizi dugu. Tradizio kultural hirukoitza aurkitzen da azken mende hauetan Euskal Herrian, hiruzpalau hizkuntzen bizigunea delako. Eta, Tx. Lasagabasterrek zion, gisa batez edo bestez ainiztasun hori behar zitaikeela kontutan hartu. Bainan, berak aitortzen zuen xede guziz helgaitza zela eta, zailtasun hori kontutan hartuz, erraten zuen bidezkoa zela ikerlariarentzat euskarazko sorkuntza baizik aztertzea euskal literatura gisa.

Bukatzeko eta laburbiltzeko, erran daiteke Tx. Lasagabasterrek «euskal literaturaren historia berritu» bat eskatzen zuela.

Euskal literaturaren historiaren eredu berritua :

Ondoko belaunaldiak osatu du Tx. Lasabagasterrek eskatu zuen « eredu berritua ». Hain zuzen, haren ikasle ohiek egina dute ekarpen hori, parte handi batean. Ondoko hiru idazlanen bitartez aipatuko dut 90-eko hamarkadatik hona egin den aurrerapena : M.J. Olaziregiren Euskal eleberriaren historia $(2002)^{7}$, J. Kortazar-ren Euskal literatura XX-garren mendean $(2003)^{8}$, I. Aldekoaren Euskal literaturaren historia (2008) $)^{9}$. Beste zenbait badira, bainan gehienetan askoren artean egindako lanak dira. Hiru horiek hautatu ditut, autore bakar batenak izanez, osotasun gehiago badutelakoan, xede teoriko eta urraspide metodologikoen aldetik.

Izenburuetarik ezagun da idazlanen arteko ezberdintasunak : I. Aldekoarena Historia orokorra delarik, beste biek XX-garren mendea bakarrik dute aztergai, gutti gora behera. Eta bestalde, garbi ageri da, sorkuntza mota batera (eleberrira) mugatzen duela bere ikerketa M. J. Olaziregik. Ezberdinak dira ere, zenbait aukera metodologikoengatik. M.J. Olaziregik obren aztertzerakoan harrerari emanen dio arreta berezia. J. Kortazarrek berriz, Europa mailan zabaldu diren "konzeptu estetiko" batzu erakartzen ditu euskal literaturaren argitzeko. Bainan, oro har, hiruek, Lasagabasterrek eskatzen zituen oinarrizko hiru aukera egiten dituzte : bat, zehaztasun intelektuala eta zientifikoa; bi, euskarazko testuen balio literarioa hautaketaren lehen kriteriotzat ; hiru, euskal literatura aztertzen dute sistema konplexu bat bezala.

\section{Eredu berritua finkatzen ari:}

- Argitalpen kontestua guziz berezia: Eredu berritu hori azken urte hauetan finkatu da eta, erran dezagun kritika akademikoan segurik gehienek onartzen dutela. Ikusi behar da kontestu guziz berezian eraikia izan dela. Pundu hontan ez naiz luzatuko, denok bizi izan dugun egoera soziohistorikoa baita. Nahas mahas, alde nabarienak aipa ditzadan, denek gogoan edukitzeko gisan :

- Aldaketa historiko nagusi zenbait gertatu dira euskal eremuan eta mota askotako instituzioak (zentzu politikoan baita ere soziologiaren arabera) agertu dira.

- Ingurumen soziokulturalaren aldaketa erabatekoa izan da, kanpoko ideien harrera mailan baita ere euskararen baloratze sinbolikoan.

- Aldaketa politikoek, soziologikoek eta ekonomikoek eragin handia ukan dute literaturaren sortze, banatze eta hartze prozesuetan eta argitalpengintzaren garapenean.

7. Olaziregi M.J., Euskal eleberriaren historia, Labayru arg., 2002.

8. Kortazar J, Euskal literatura XX-garren mendean, Prades arg., 2003.

9. Aldekoa, I., Euskal literaturaren historia, Erein arg., 2008. 
- Euskal ikasketak antolatuak izan dira bi aldetako Unibertsitateetan eta euskara sartu da eskola sisteman. Ondorioz, era askotako eskaerak agertu dira eduki pedagogikoen aldetik, euskal literaturaren arloan besteetan bezala.

- Unibertsitateko ikasle eta irakaslegaien formakuntzarako baita ere publiko zabalago baten jakitate eskaera bati erantzuteko, gisa ezberdinetako ikerketak eta idazlanak agertu dira, idazle eta unibertsitarioen eskutik.

- Euskal literaturen historiaz egin diren akerketa lan horietan eredu edo "patroi" bat azaldu da, urteak joan arau.

- Lana mugatu beharrez, gorago aipatu ditudan hiru idazlanen (I. Aldekoarena, J. Kortazarrena, M.J. Olaziregirena) baitan oinarritu naiz eredu berriaren inguruneak erakusteko.

- "Patroi" berriaren oinarri "kontzentzualak": Ondoko hiru punduetan bilduko ditut «patroi » berriaren oinarri « kontzentzualak » eta ikusi behar da bilduma bat baizik ez dela :

- Literaturaren "definizio" gaurkotua zabaldu da : "sail eta ihaduera autonomo" gisa definitua da. Ondorioz, gorago aipatu hiru autoreak, "kanon bildu" baten alde dira, salbu, bistan da, idazle garaikideentzat.

- Euskal literaturaren historia "objeto" konplexu gisa hartua da, sistema bezala ; giza zientzietatik (soziologiatik batez ere) heldu diren konzeptuen bitartez aztertzen da.

- Toki nasaia, nasaiena orrialde kopuruaren aldetik, eskaintzen zaio sorkuntza garaikideari.

\section{Eredu berrituaren ekarpena:}

- Paradigma aldaketa: garaikidetasunari lehentasuna. Erran daiteke, azken urte hauetan, paradigma aldaketa bat izan dela. Garaikidetasunari emana izan zaio lehentasuna, euskal gizartean eta kulturan oro har, literaturan, sorkuntza mailan, baita ere, euskal literaturaren historian.

Lehentasun horren neurtzeko, har dezagun adibidez I. Aldekoaren liburua. Euskal literaturaren historia orokorra aurkezten du, hots bost mende. Azken berrogeitahamar urteek, bigarren gerlatik landa Aresti, Mirande eta Txillardegirekin hasten diren garai moderno eta garaikideek, liburuaren erdia hartzen dute nonbait han. Eta, beti liburu berean, XX-garren mendeko azken hogeitahamar urteek bederatzi sartze ezberdin badituzte, liburuak osoak 21 bat sartze dituelarik. Abantxu sartzeen erdia azken mende laurdenarentzat : aurreko historiekin konparatuz periodizazioa era bat aldatua da eta badirudi literatura garaiak gero eta lasterrago iragaiten direla. Eta, oreka bertsua aurki daiteke XX-garren mendeko literatura mailan, J. Kortazar eta M.J. Olaziregiren liburuetan.

Beste seinale bat : narratibari ematen zaion ardura berezia. Narratiba, genero nagusia bilakatua da bigarren gerlatik hona euskal literaturan besteetan bezala, eta literaturaren historiek hari diote lehentasuna ematen, nahiz fenomeno aski berria den gurean.

Beraz, erran daiteke gaurkotasunari emana izan zaion lehentusanak ondorioak ukan dituela hiru mailetan: periodizazioaren aldetik, baita ere generoen tratamenduan eta orekan. Ohar gaitezke hirurogeitahammarreko hamarkadan hain garrantzitsua zen "hizkuntza literarioari" buruzko eztabaida trenkatua bezala agertzen dela, ezbaitute hiru autore horiek gaurko literaturaren azterketa egiterakoan batere aipatzen gehiago.

Bistan dena, aurreko punduek arazo teoriko eta tekniko batzu idekirik uzten dituzte eztabaidarako, hala nola autore zahar eta modernoei eskaintzen zaien tokia eta garrantzia euskal literaturaren garapenean, baita ere eduki duten eragina sorkuntza garaikidearen baitan.

- Lehia zientifikoa: Lasagabasterren eskaera. Gaurkotasunaz bestalde, bigarren ezaugarri bat aipa 
daiteke « eredu berrituan ». Tx. Lasagabasterrek eskatzen zuen egunaratze teorikoa hain zuzen eta zehaztasun intelektuala eta zientifikoa dira bigarren pondu hontan biltzen ahal direnak. Kanpoan erabiliak diren metodologiak euskal literaturaren azterketari egokituak izan diren 80-eko hamarkadatik hona : semiotika, harreraren estetika eta irakurleari buruzko teoriak, literaturaren soziologia, etb. Hor dira, bihurgune teoriko horren lekuko ordutik hona aurkeztuak izan diren tesia nagusiak, A. Toledo, J. Kortazar, K. Otegi, L. Otaegi, A. Arkotxa, M.J. Olaziregi, I. Aldekoa, U. Apalategi, etb. bezalako ikerleek argitara eman dituzten ikerlanak.

- Urte horiertan egin diren azterketa monografikoak (Tx. Agirre, Lizardi, Aresti, Atxaga eta abar.) erabiltzen dituzte beren lanean, bainan, I. Aldekoarentzat M.Hernandez Abaituak liburuaren aurkezpenean azpimarratzen duen bezala, hustuneak -eta asko bada oraindik- berek betetzen dituzte.

- Bestalde, erabili dituzten erreferentzia teorikoak garbiki aipatzen dituzte, aukera metodologikoak ere. Lan horri, bere Euskal eleberriaren historiaren, lehen kapituluak eskaintzen dizkio molde guziz zehatzean M.J. Olaziregik eta gauza bera egiten du J. Kortazarrek Euskal literatura XX-garren mendean liburuaren atarian ezarri duen sartze metodologiko luzean. Eta, kezka teoriko horrek hirugarren azken pundura eramaiten gaitu.

- Euskarazko literatura mailan materiala ugaritu da azken urte hauetan: sorkuntza mailan tituluen gorakada, idazlan mota edo generoen aniztasuna alde batetik eta, bestaldetik, bizi literario baten antolaketa edo bederen, antolaketa bati buruz eginak izan diren lehen urratsak. Maila hortan ere, indar berezi bat egin dute aktualitateak eta, harekin batean, egoera soziokulturala berriak ekartzen zuten emaitza, kontutan hartzeko argitaratu dituzten ikerlanetan.

\section{Eredu didaktikoa: transmiziorako pentsatua.}

Gaurkotasuna, zehaztasun intelektuala aipatuak ditut. Hirugarren ekarpen bat ikusten ahal da « euskal literaturen historia » sailean deitzen dudan « eredu berritu » hortan : alde edo alderdi didaktikoa. Hiru autore horiek irakasleak dira Tx Lasagabaster bezala, hiruak unibertsitatean eta, erran daiteke, historia literarioaren hastapeneko helburua gogoan edukitzen dutela, hots, transmiziorako pentsatua dutela beren lana.

Ageri da transmizio lan hori funtsezkoa iduri zaiela eta interesgarria da ikustea bi mailetan ari direla. Alde batetetik euskaraz bertako publikoarentzat, erran nahi baita Euskaldunentzat, bestaldetik erdaraz kanpokoentzat.

Bertakoa aipa dezadan lehenik : gaurko egunean, erran nahi baita euskara eskola sisteman sartuz geroz, badakigu norentzat ari garen lanean euskal literaturaren historia lantzen dugularik : gure unibertsitateko ikasleentzat, irakasle, kazetari eta beste bilakatuko direnentzat eta haien bitartez, lizeoko ikasleentzat ; ahantzi gabe, bistan dena, publiko zabalago baten jakin minarentzat ere arizan behar dela.

Kanpoko publikoa aipatzen dudalarik, autore horiek bi edo hiru hizkuntzetan ari direla azpimarratu nahi dut, barnekoentzat egiten dituzten liburuak itzuliz eta egokituz. Atzerrira joaten dira ere, euskal literaturaz klase emaitera. Kanpokoentzat, konparatismoaren bidea hartzen dute, bertako erreferentzia literarioak emanez eta, denbora berean nazioen artean erabiltzen diren konzepto eta metodologiak baliatuz.

Lan didaktiko hori funtsezkoa da arrazoin batengatik : literaturak eta haren historiak nola ez, badu oraindik -nahiz zalantzan den XXI-garren mende hastapen hontan- balio sinboliko handia. Haren inguruan, bada, dudarik gabe, legitimitate kulturalaren aldetik, lehia nagusi bat jokoan dena. Legitimitate kulturala jokoan dago barneko eremuan, Euskaldunek hobeki ulert dezaten beren arte- 
ko zenbaitzuek, idazleek kasu hontan, zer ikuspegi mota zabaldu duten denek bizi ditugun arazoei buruz. Eta, alde hortarik, ez da ahantzi behar Literaturaren historia dela eremu historiko bakarretarik ezpada bakarra garai historiko ezberdinetako Euskaldun guziak bateratzen dituena, literatura euskaraz idatzia delako. Orroit gaitezen K. Mitxelenak "ardatz linguistikoa" zuela oinarritzat hartu bere lanean, beste ezaugarriak ixilduz.

Eta legitimitate kulturala jokoan dago ere, bistan dena kanpokoei begira : ezpaita bizitzen ahal luzara konparaketarik gabe eta kanpokoek emandako ezagutzarik gabe.

\section{Konklusioa}

Datu bilketa lan bat egin dut ikusteko zenbatetaraino bete den Tx. Lasagasterrek finkatu zuen programa. Orain, eredu berritu horren deskribapenetik hara, haren azterketa sakona egin behar da ekarpen eta gabezien argitzeko gisa. Egitekoa da ere, eredu berriaren inguruan izan diren eztabaiden aipamena. Ondoko lan baten gaia izanen da. 
